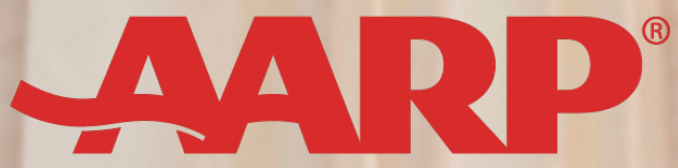

\title{
How Hispanics Manage Unexpected Financial Challenges
}

2019 AARP Survey of Adults Ages 30 and Older

\section{Introduction}

A critical component of financial security is the ability to weather financial emergencies, such as a necessary car repair or temporary loss of income. Regardless of income level, age, gender, or race/ethnicity, all U.S. households may experience unexpected financial challenges. However, this fact sheet focuses on unexpected financial challenges among Hispanic adults. It is based on findings from a national survey of U.S. adults ages 30 and older. ${ }^{1}$

More than half of Hispanics ages 30 and older reported experiencing an unexpected financial challenge in the past year. Among them, more than half also reported experiencing more than one challenge. Notably, Hispanics (55\%) were more likely than their White peers (39\%) but less likely than their African American peers (61\%) to report experiencing an unexpected financial challenge.
Survey findings show over half of Hispanics ages 30 and older experienced an unexpected financial challenge in the past year.

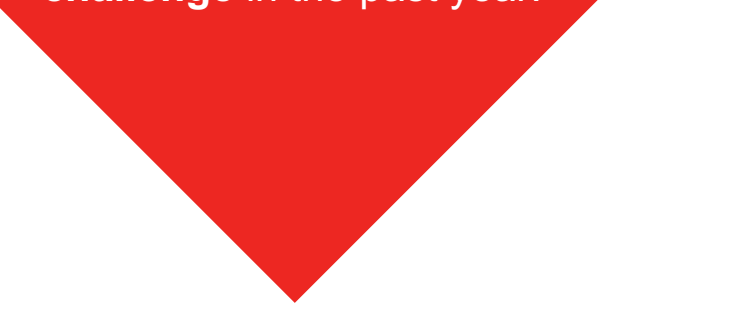


Percentage of Hispanics who experienced an unexpected financial challenge in the past 12 months

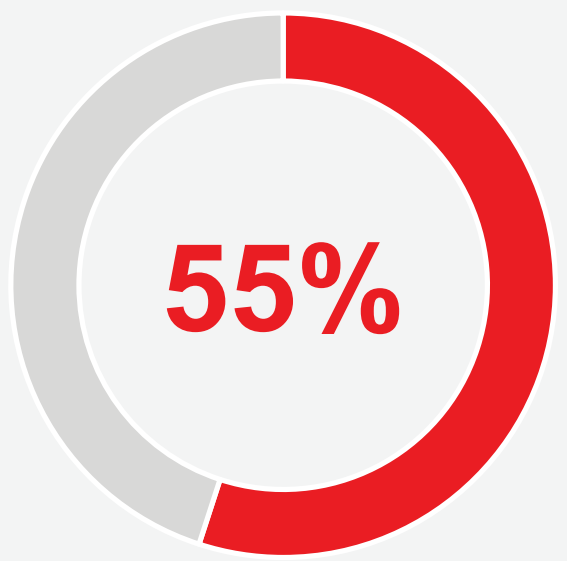

Q1. In the past 12 months, did you, an immediate family member or someone else in your household experience an unexpected financial challenge that caused a significant strain in your budget or your ability to pay your bills? $(\mathrm{n}=730)$
Number of unexpected financial challenges Hispanics experienced in the past 12 months

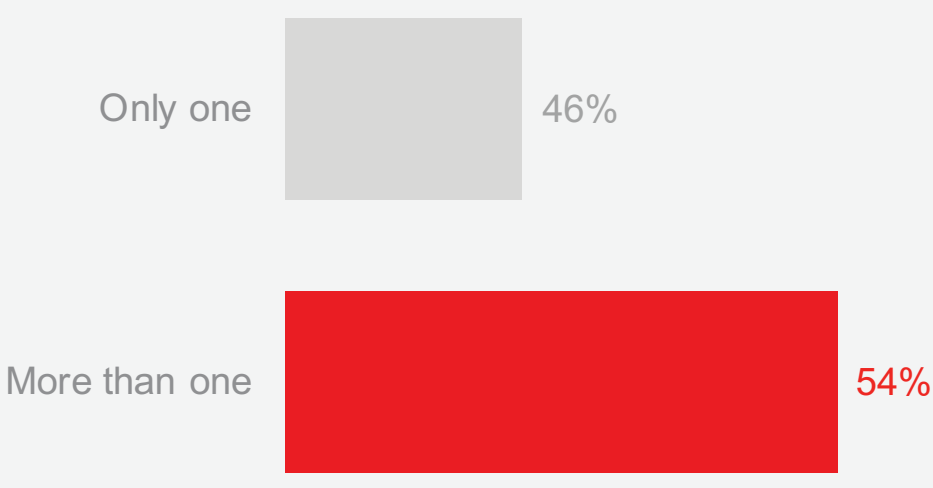

Q2. In the past 12 months, how many unexpected financial challenges have you experienced that caused a significant strain on your budget or your ability to pay your bills? $(n=400)$

The leading cause of an unexpected financial challenge among Hispanics was a loss of income, followed by unforeseen expenses. Among these expenses, necessary repairs and medical expenses topped the list.

Expenses causing an unexpected financial challenge for Hispanics

Necessary repair

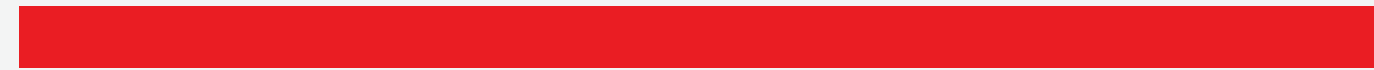

Medical expenses

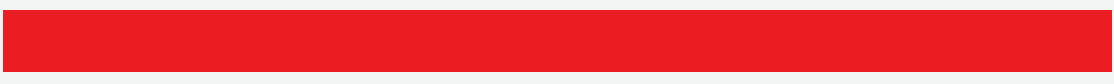

$27 \%$

Educational expense

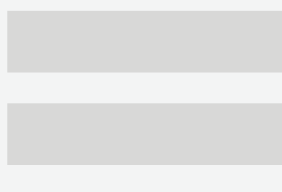

Legal expense

$$
7 \%
$$

Tax bill

$6 \%$

Caregiving expense

$3 \%$

Other*

$10 \%$

\section{$7 \%$}

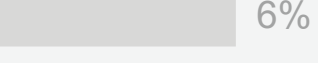

$15 \%$

*NOTE: "Other" expenses include auto accident, vet bill, bank overdraft fees, death of a family member, tax bill, government shutdown, bought a home, etc.

Q3. What was the reason for your financial challenge? $(n=400)$

Q4. Specifically, what was the large expense that caused your financial challenge? $(n=235)$ 
To help resolve their financial challenge, a majority of Hispanics reported making trade-offs, such as cutting back on expenses, delaying payment of bills, withdrawing money from their bank account, and working extra hours to increase their income. Notably, a third asked for an affordable payment plan or reduction in the amount owed.

Top 10 actions taken by Hispanics to resolve their unexpected financial challenge

Cut back on expenses

Delayed paying one or more bills

Withdrew money from a bank checking or savings account

Worked extra hours/increased household income

Used a credit card

Sold something

Borrowed from a friend or family member

Paid some or all the cost with cash

Asked for a payment plan/reduction in amount owed

Used long-term savings/investment accounts

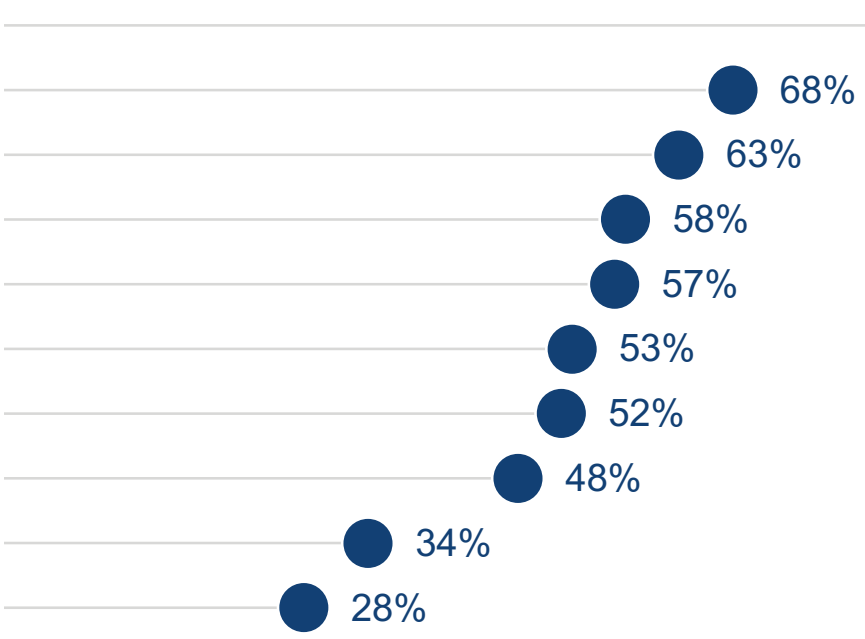

Q12. Did you do any of the following to help with your financial challenge? $(n=400)$

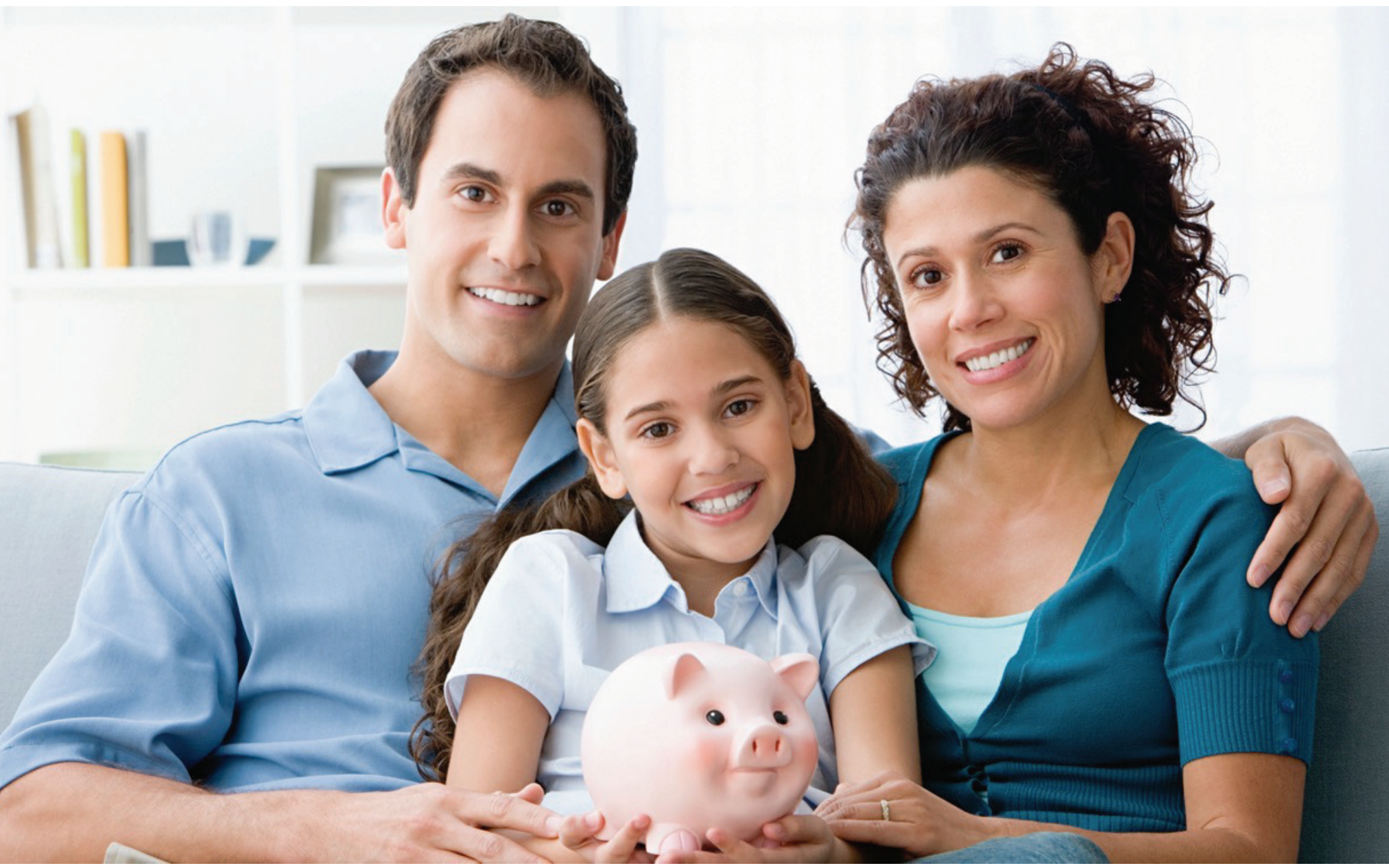


Despite their financial setback, nearly half of Hispanics who had experienced an unexpected financial challenge in the past year reported feeling confident that their household is doing what's necessary to meet their longer term financial goals.

Confidence about meeting longer-term goals among Hispanics who experienced an unexpected financial challenge in the past 12 months
- Very confident
- Somewhat confident
- Not too confident
- Not at all confident

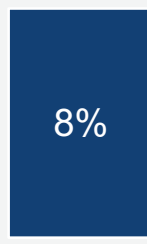

$38 \%$

$32 \%$

Q22. Thinking about your household's longer-term financial goals such as saving for a vacation, starting a business, buying or paying off a home, saving up for education, putting money away for retirement, or making retirement funds last... How

confident are you that your household is currently doing what is needed to meet your longer-term financial goals? $(n=400)$

In addition, nearly half (46\%) of Hispanics who experienced an unexpected financial challenge reported putting at least some money aside each month as savings. Among those who are saving, nearly two in five are saving for an emergency or rainy day.

Savings priorities among Hispanics who experienced an unexpected financial challenge in the past 12 months

Emergencies or rainy days

Retirement

A major purchase

Investing or getting ahead

Helping family or children

No particular reason

Upcoming educational expenses (school or college)

Heirs as an inheritance

Other

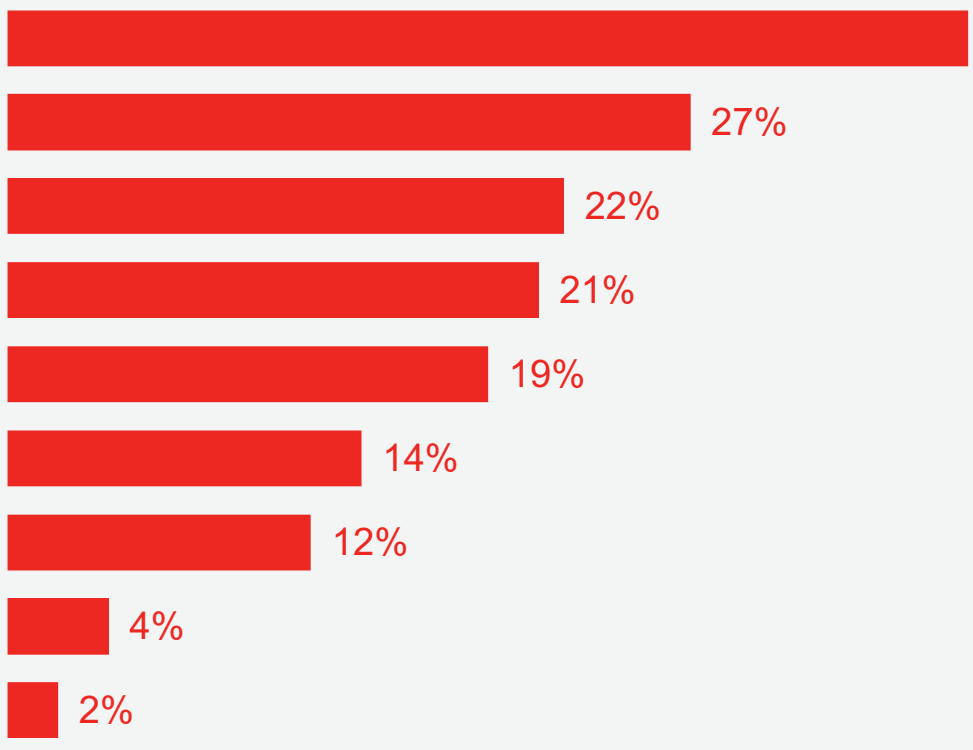




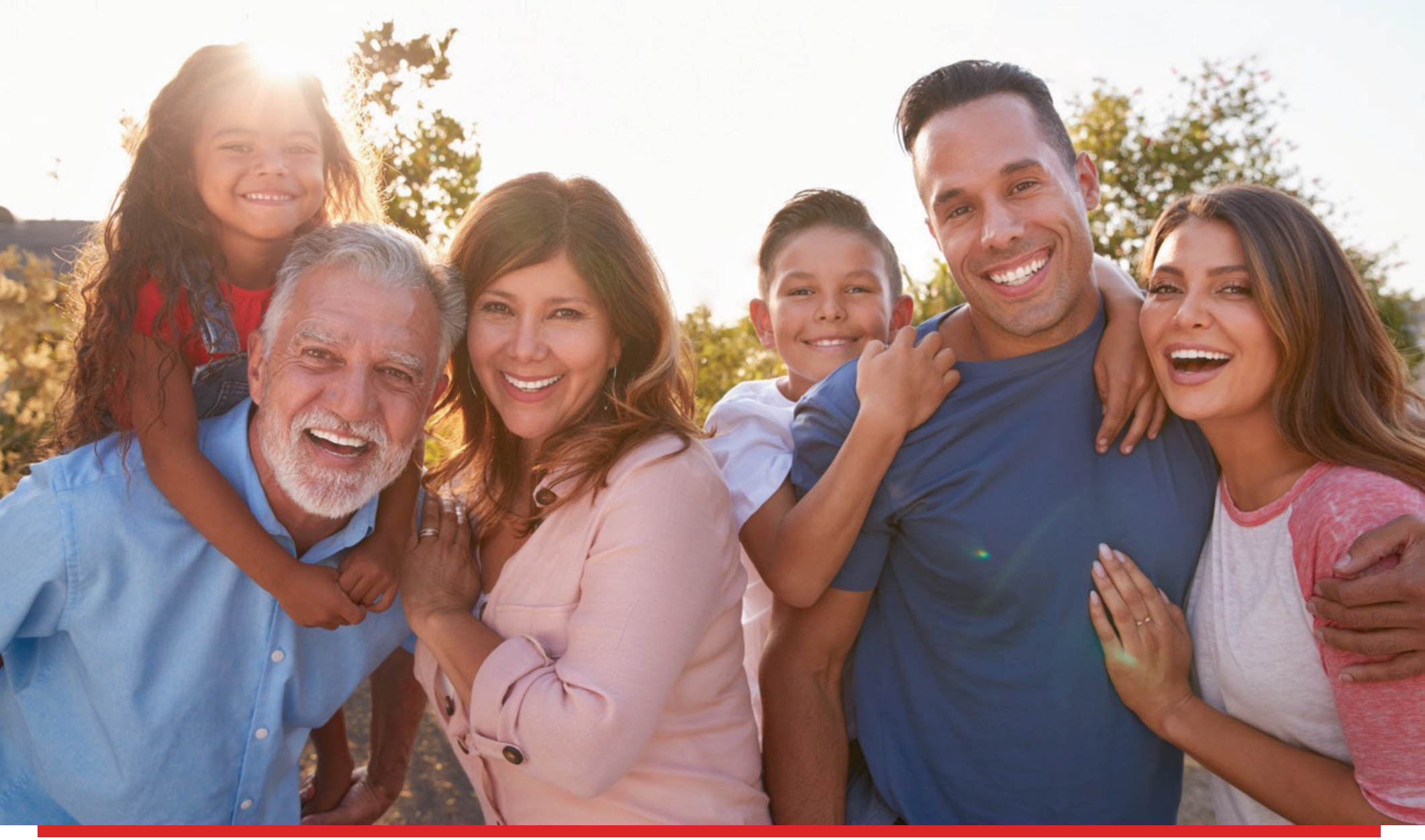

\section{Methodology}

This fact sheet is based on data gathered from a larger general population survey of U.S. adults who had experienced an unexpected financial challenge. The survey was conducted by NORC at the University of Chicago on behalf of AARP. Sample members, including oversamples of African Americans and Hispanics, were randomly selected from the AmeriSpeak® Panel, a probability-based panel developed by NORC at the University of Chicago. AmeriSpeak is designed to be representative of the U.S. household population. Among the 1,697 adults completing the survey, 400 were Hispanic. Hispanics may be of any race.

Interviews for this survey were conducted between September 4, 2019 and September 19, 2019, with adults ages 30 and older, representing the 50 states and the District of Columbia. Once the sample was selected and fielded, and all of the study data were collected and made final, weighting was used to adjust for unequal sample selection probabilities under the sample design, survey nonresponse, and frame coverage. Frame coverage was adjusted through raking to align the weighted sample to the population by age, gender, education, race/ethnicity and Census Division. Post-stratification weighting benchmarks were obtained from the 2018 Current Population Survey. The weighted data of the full sample reflect the U.S. population of adults ages 30 and older. The margin of error for the full sample is \pm 3.51 percent at the $95 \%$ confidence level. Although the margin of error for the Hispanic subset is unavailable, it would be larger than that of the full sample. 